\title{
Reform and Practice of Innovation Ability in the Cultivation of Students
}

\author{
Lin Mei, Wu Wei, Wang Changwei, Liu Yongqiang \\ Air Force Engineering University Aeronautics and Astronautics Engineering College \\ Xi'an, Shaanxi, China \\ E-mail: 510486495@qq.com
}

\begin{abstract}
For the needs of training the talents' ability of serving maintenance personnel position, new ideas of cultivating the students' innovation ability are put forward in this paper. A set of construction guidelines consists of 'Teaching staff construction as the guide, Systemic teaching design as the traction, Teaching content reform as the core, Teaching pedagogy innovation and methods reform as the breakthrough, Teaching resources construction as the support' is specified in this paper. Construction objectives include the four aspects as 'Teaching objectives adjustment, Teaching contents optimization, Teaching methods reform, Teaching experiments integration' are made. From gaining the construction objectives, the training model of trinity of knowledge, ability and quality is established. Innovative teaching progress as 'Integrating quality resources, Collaborating teaching and research, Associating personnel training' is made. We have achieved some performance in cultivating the students' innovation ability.
\end{abstract}

Keywords-Training Model, Innovation Ability, Comprehensive Quality, Scientific Research Consciousness, Teamwork Ability, Independent Experiment

\section{INTRODUCTION}

Training the students specializing maintenance engineering is among the tasks of our college. With rapid development of the equipment, higher and higher requirements for the crew are required. The situation requires the students we cultivated should enhance their innovation consciousness, innovation ability and practice ability. And innovation ability cultivating of students is among the reform objectives in the field of educational objectives, educational program, instructional models and practical training. All reform work we do is surrounding the revision and implementation of the program of talent training. The goal of the program is improving comprehensive quality and engineering practice ability and innovation ability of our students. From the program we expect to construct the training model of trinity of knowledge, ability and quality will be established.

In order to meet the needs of social development, innovation and reform of the original teaching model are made and new teaching ideas are put forward. On the basis of the original teaching model, whose particular emphasis is knowledge impartment and basic skill training, trainings of innovation consciousness, innovation ability and practice ability are given added weight. All the trainings above can enhance the students' ability to discover, analyze and solve problems by themselves, and develop their rigorous scientific attitude, scientific style and thinking methods. All the methods can lay a good foundation on enhancing their innovation ability on maintenance, using and management of equipment.

Such four goals as teaching objectives adjustment, teaching contents optimization, teaching methods reformation and teaching experiments reformation set, we have taken the following measures to achieve them.

\section{TEACHING OBJECTIVES AdJUSTMENT AND REFORMING MEASURES DEVELOPMENT}

Focus on cultivating the students' innovation ability, according to training requirements of laying solid foundation, orienting development, emphasizing innovation and cultivating ability, we established three cultivation systems as the followings.

\section{A. Mechanism of Scientific Research Consciousness Cultivation}

In the current Higher Education system, under the guidance of their supervisors, master degree candidates and doctorate students (PHD) can participate in some subject research and academic work, but undergraduates seldom have opportunities to participate in those high tech and high investment-oriented basic research and large-scale scientific research projects in contrast. The situation cause the undergraduates' scientific research consciousness scarce and research capacity insufficient. So the system is designed to let undergraduates participate in research, in which the teachers leader undergraduates to participate in scientific and academic research, urging them into specialized field as soon as possible. We encourage each undergraduate should at least master a kind of software, learn a set of scientific research methods and publish a paper under the teachers' guidance.

For new students, it is required that every teacher should report his relevant research topics and announce them among the students after summary. According to their abilities and interests, the students can select their mentors. After a two-way choice, the teachers will assign tasks to the students according to their research direction and contents. The teachers and students will meet on a weekly basis, having relevant communication and mastering schedule. At the end of each academic year, students should complete such relevant technical documents as research reports, technical papers and patent applications as reply of the topic. 


\section{B. Mechanism of Innovation Ability Cultivation}

In order to enhance students' innovation ability, we should encourage them to participate in wide-ranged independent scientific innovation activities and various types of competitions.

Based on the Mechanical Engineering Laboratory, we guide students to participate in 'Second Class' and various competitions, require them to complete all work insist in their performance including design, manufacture, installation, debugging and composing specifications, completing PPTs and videos for report. Through participating in the activities under the teachers' guidance, students can learn a series of practical section and content as the followings: to have enough theoretical study and comprehensive analysis on their design schemes, to determine the optimal design scheme, to manufacture components and turn theory into actual objects, to debug a finished product, to constantly amend, improve and perfect the theoretical design scheme to obtain optimization products during debugging, to compose report materials, etc. In the process of translating theory into reality, the students' understanding and mastering of theoretical knowledge are deepened. And also the students' practical ability is improved, from unskilled to skilled and from nonconsolidated to consolidate. Thus the innovation spirit and practice ability are carried out in practice and the goal of combining theory with practice is obtained.

\section{Mechanism of Teamwork Spirit Cultivation}

To construct the training model of trinity of knowledge, ability and quality, in practice of teaching and engineering training, completion of the works is more often than not, they can complete alone. It is a process of collective solidarity and cooperation, learning from each other. Lots of ideas completed depend not on one's own intelligence but on a team's collaboration.

Usually, a team comprises of 5 to 10 members and team leader responsibility system is implemented in the team. Two students will be specified as senior and deputy leader of the team and everyone in the team has his own specific responsibility. All members in the team brainstorm for the problems and difficulties appear in engineering trainings and competitions and solve them together. This will not only urge the students inspire mutually and find new clues, but also enhance their corporate responsibility, uniting all forces and mobilizing all positive factors in full measure to accomplish the task.

\section{TEACHING CONTENTS OPTIMIZATION AND TEACHING METHODS INNOVATION}

In order to obtain our goals, we usually take such actions as the following: classic contents refining, old contents updating, frontier contents enriching, relative contents merging, innovative contents highlighting, etc. Thus teaching and scientific research will be merged into classroom teaching promptly. Take the teaching material 'Basic Theory of Machines and Mechanism' as an example, in order to better serve the rapid development of airport equipment, we have merged such active equipment as gearboxes, altimeter, undercarriage of helicopter into sample questions and exercises.

Old teaching contents system reformed, common rules and basic methods of engineering design highlighted, strengthened modern design and advanced tools, deriving purely theoretical deduction, we've adjusted our course system. In the adjustment, except for some backbone courses as 'Basic Theory of Machines and Mechanism', 'Course Exercise for Mechanical Design 'are retained, some new courses as 'Mechanical Innovation Design', 'Computer-Aided Drafting' are added. Recommendation for the latest designing methods and innovation design are added timely to cultivate the students' ability to analyze and solve problems, enhancing their comprehensive quality.

\section{Advanced Teaching Resources Mining, Teaching METHODS REFORMING}

Transferring the mode of knowledge imparting in classroom to the combined mode of heuristic and open knowledge imparting, we've emerged open independent innovation design into classroom teaching, experiment and extracurricular classroom. Making full use of modern teaching equipment and using multimedia instruction in classroom teaching, we can increase the amount of knowledge and teaching vividness and stimulate the students' learning motivation. Establishing new courses as 'Mechanical Innovation Design' and 'Computer -Aided Drafting', building new mechanical engineering laboratories and implementing open management, we've expanded the students' horizons greatly and stimulated their interest in study.

\section{A. Reforming Theoretical Teaching, Stimulating Study Interest and Fostering Ability}

Under the traditional teaching system, the teachers impart knowledge to the students by lecturing and they rather orientate themselves to classroom manager and knowledge implanter. Under the system, the teachers are the subject of teaching and the students are in a passive position on the other hand. The students can't go deep into exploration and research of teaching contents, resulting in low efficiency of classroom teaching. Orientation of the teachers hindered further reform of teaching and hampered the pace of education progress.

We activate students in teaching methods, fully motivating their learning passion, mobilizing their learning initiative and positivity. Also we cultivate the students' to acquire knowledge independently on the basis of learning ability cultivation, innovate to realize the diversification of teaching methods. We have independently researched and developed series of digital teaching resource as multimedia teaching materials; online courses and test database, etc., and established VRT Laboratory. Using a variety of means and various forms of education we combine speak and read with operation. We also connect abstract theoretic knowledge with practical application, try hard to make the students grasp knowledge in all aspects in specific situations and decrease the slope of understanding. All we do is to enhance teaching attractiveness.

On the test database' aspect, according to the examination requirement of the curriculum standards and different text 
types, we establish more than 1000 questions. According to various require, we make random combination of test papers for exercises or examinations.

\section{B. Stressing Practical Teaching, Developing Practical Engineering Ability}

The students' innovation and practice cultivation must start from engineering awareness and ability, which come from practice.

During reformation and construction of experiment teaching and practice teaching, center on the goal of training the students' practical engineering ability, a practical education system composed of experiment course, integrated engineering training, curriculum design and graduation project, internship and extracurricular technological activities is established. According the rule that the students master and apply their knowledge, the system can be divided into three parts, which are synthetic basic experiment and practice teaching, subject basic experiment and practice teaching, professional and oriented basic experiment and practice teaching. Subject basic experiment and practice teaching is composed of such course experiments as Principal of Machinery and Mechanical Design, curriculum design as Mechanical Design, Metalworking Practice and Cognizing Practice, etc. Professional and oriented basic experiment and practice teaching is composed of Equipment Maintenance Practice, Professional Orientated Course Design and Graduation Project, etc.

\section{REFORMING EXPERIMENT, ESTABLISHING INDEPENDENT EXPERIMENT PLATFORM}

According to the requirement of 'Laboratory Construction Standard', associating with the characteristic of experiment teaching, we've established Mechanical Engineering Laboratories composed of the four parts as Mechanical Designing Basis Lab, Material Science Foundation Lab, Metalworking Practice Station, and Mechanical Designing Innovation Lab. From the laboratories' construction, diversity, comprehensiveness and independence of experiment teaching is achieved, and experiment teaching being combined with theory teaching organically. The teaching model of Guiding Exploring- Testing- Mastering comes into reality, under which experiment teaching procedure and method is optimized and innovation ability of the students is cultivated.
Persevering in and out of class keeps successive, extending practice space from single mechanical disciplines to multidisciplinary synthesis meeting the needs of our society, we choose backbones from the students to lead them participate in 'Three Great' tasks (they are topics of great significance, of great valued and of great difficulty) on the basis of 'Three Littles' (which are Little Invention, Little Innovation and Little Production).

\section{CONCLUSIONS}

In this paper, the construction principles of 'Teachers' Team Building as Guide, Systematical Instructional Design as Traction, Teaching Content Reform as Core, Teaching Method Innovation and Means Reformation as Breakthrough, Teaching Material Construction as Support' is made. From a series of reform measures, the students can learn more knowledge that the books can't give them, and also they can obtain more inspiration of innovation in many aspects. We'll make more chance to let the students participate in specific research and practice activities, making them more quickly get into actual work, obtaining the purpose of integrating theory with practice and conducting practice with theory. Otherwise, there's no made regulation for education innovation, it is still in step-bystep process of groping and exploring. In all, the ultimate objective various methods and means used is to cultivate talents with innovative spirit and innovative ability.

\section{REFERENCES}

[1] HE Wen-sen,YANG Hua-jun,etc.Undergraduate Cultivation of Innovative Practice Ability. Research and Exploration in Laboratory,2015,34(7):94-97.

[2] Ma Dazhong,Cui Jin, etc. Exploration and Practice on Innovative Experimental Projects Based on Cultivating Innovative Talents. Experimental Technology and Management, 2014,31(9):33-36.

[3] WANG Li,CHEN Jiang-bo, etc. Practical Ability Training and Scientific Research Combining with Teaching.Research and Exploration in Laboratory,2011,30(8) :112-114,162.

[4] TANG Jia-le,CHENG Fang,etc,Cultivation of Practice Ability and Innovation Ability of College Students for Quality Education. Research and Exploration in Laboratory, 2013,32(1):88-89,135.

[5] WangSheng huai,LiTukun,etc, Cultivating Mode of Comprehensive Innovation Ability for Undergraduates Based on Scientific Research Outcomes.Experimental Technology and Management, 2015,32(12):912 . 